is perhaps an uncomfortable (but not entirely unprecedented) aspect. Alternatively, the authors consider a mechanism based on direct transfer of a proton from the water molecule to the $\gamma$-phosphate. In both models, the pentacovalent structure is stabilized by interactions with arginine and glutamine side chains, with the latter adopting different tautomeric forms in the two mechanisms.

Although these suggestions are consistent with much of the evidence available on the chemical mechanisms of GTPases, some facts and results do not fit into the picture. For example, the structurally related EF-Tu has an essential histidine at the position (204) corresponding to Gln 200 . In $21^{\text {ras }}$, replacement of Gln 61 by the unnatural amino-acid nitroglutamine, in which the carboxamide is replaced by a nitro group, is reported to result in a protein with normal GTPase activity and even normal sensitivity to activation by GAP (GTPase activating protein) ${ }^{12}$. This group is even less likely to act as a proton acceptor than glutamine and could not interact in an analogous manner with the pentacovalent intermediate, although some degree of stabilization may be possible. Perhaps the final clues to the mechanisms, which may not be identical for all GTPases, will come from a detailed study of the structure and kinetics of such modified proteins.

RogerS. Goody is at the Max-Planck-Institut für Molekulare Physiologie, Postfach 1026 64, 44026 Dortmund, Germany.

\title{
Damping seasonal variations
}

\section{Paul Valdes}

From a geological perspective, our present climate is unusually varied. For much of the distant past, climate appears to have been substantially warmer, particularly at mid- and high latitudes. For instance, during most of the past 250 million years, there have been no polar ice caps. The most recent period of warmth occurred in the early Eocene (about 50-55 million years ago), when geological data suggest that even in winter, continental interior temperatures remained above freezing. In this sense the Eocene climate is said to be equable, with no seasonal extremes. But studies using general circulation models (similar to those used for future climatechange predictions) simulate Eocene winter temperatures of $-30^{\circ} \mathrm{C}$ or colder. This has led to a vigorous debate, with modellers questioning the reliability of the geological data and geologists querying the accuracy of the climate models. Lisa Sloan, writing in Geology ${ }^{1}$, now suggests a possible solution to the problem: pay more attention to the details of the ancient landscape.

Evidence exists for large lakes in North America during the Eocene, and so Sloan included a representation of these lakes in a general circulation model simulation. The presence of the lakes acts to ameliorate the bitter cold in winter, producing a climate downwind of the lakes similar to that of maritime regions. The resulting warmth brings the models and data into much closer agreement. The changes caused by the lakes are as large as those caused by changing the concentration of atmospheric carbon dioxide, or changing ocean heat transport.

The work is the latest illustration of the (generally) beneficial interactions between climate modellers and geologists.
The story starts in the 1970s and early 1980 s. Using a variety of palaeoclimate indicators, ranging from the habitats of ancient crocodiles to the types of plant fossil found in different regions, the geologists assembled a convincing picture of a climate that was considerably less extreme than the present ${ }^{2}$. Indeed the Eocene was not the only equable period. Much of the Mesozoic era seems to have been very warm, culminating in a maximum in the mid-Cretaceous (about 100 million years ago). There was also evidence for high carbon dioxide concentrations during these periods ${ }^{3}$, thus adding to concern about future global warming.

These dramatic differences between present-day and past climate inspired a number of climate modellers to investigate the cause of the equability ${ }^{4,5}$. Their results were surprising. Despite many attempts, no climate model was able to reproduce the necessary degree of equability, particularly in continental interiors far away from the moderating influence of the ocean. It was suggested that either there was a fundamental flaw in our understanding of climate and climate change, or the concept of an equable continental interior had to be abandoned ${ }^{5}$.

Piqued, the palaeoclimate community were spurred into further investigations. Using more sophisticated techniques based on the morphological characteristics of leaves, they confirmed that the climate of continental interiors was indeed equable $^{6}$. The models appeared to be wrong. But there are some caveats. The most solid data are for the North American region. Less is known about the other continents. Further, even for North America, the data are heavily biased towards the western side of the continent, so the problem of equable Eocene continental interior climates largely boils down to understanding the climate of the western United States.

This is where the influence of a large lake (in the vicinity of Green river in the western United States) becomes important. The addition of this lake into the climate model brings the simulations into closer agreement with the geological data. The lake has a large heat capacity, so it is slow to cool in winter and slow to warm in summer.

So is this is the end of the story? No! Even with the lake, the seasonal range of temperatures is generally too large. Also the size of the imposed lake is potentially controversial. The general climate model has a resolution of $4.5^{\circ}$ in latitude and $7.5^{\circ}$ in longitude, and the lake occupies roughly two grid points. This is large - up to four times the size of one of today's Great Lakes - and will need clear geological validation. Further, it must be confirmed that all of the 'equable' data are of the same age as the lake. Should any of them be earlier or later than the ages of the lake, then the problem of equable climates will remain. New data are also beginning to arrive from Russia. This will be yet another test of the model predictions, in a region where the model indicates extreme winter cold.

The results also pose another question. When is a climate model wrong? The newer simulations are in better agreement with observation. It is therefore fair to say that the original climate model was wrong. However, the error was due not to inaccuracies in our understanding of the processes that control climate but to imprecise knowledge of the boundary conditions for the model - the amount and position of large expanses of water. The former error would spell doom to model predictions for future climate change; the latter just shows an incomplete understanding of climate history.

The agreement between model and data shows us that we should have some confidence in the ability of computer climate models. It also shows the power of combining modelling and data studies of palaeoclimates. We now have the beginnings of a self-consistent picture of the climate of the Eocene, where we understand both the climate change and its causes.

Paul Valdes is in the Department of Meteorology, University of Reading, Whiteknights, Reading RG6 2AU, UK.

\footnotetext{
1. Sloan, L. C. Geology 22, 881-884 (1994).

2. Frakes, L. A. Climates Throughout Geologic Time (Elsevier, Amsterdam, 1979).

3. Berner, R. A. Am J. Sci. 291, 339-376 (1991)

4. Barron, E.J. Earth Sci. Rev. 19, 305-338 (1983)

5. Sloan, L. C. \& Barron, E. J. Geology 18, 489-492 (1990)

. Wing, S. \& Greenwood, D. L. Phil. Trans. R. Soc. London B341, 243-252 (1993).
} 